Introduction National Institute of Clinical Excellence (NICE-UK) guidelines covering sedation for diagnostic and therapeutic procedures has laid out recommendations for pre-sedation preparation, monitoring during the sedation along with training and skills required for health care professionals.

The following survey was conducted to identify the sedation practices in various centres across UK.

Methods Online questionnaire based on the Key Priorities of implementation (KPIs) of the guidelines. Our centre was excluded. Results 20 units participated in the survey. The pre-sedation check list for most of the centres ( 94.7 to 100\%) took into account medical background, anthropometric \& airway assessments; however, only $6(31.6 \%)$ centres included psychological and developmental status. NICE (UK) recommends anesthetist advice for sedating children $<1$ year- only $2(10.5 \%)$ responses confirmed this. 8 centres $(42.1 \%)$ ensured that sedation process was overseen by 2 healthcare professionals. In 5 centres (26.3\%), the professional delivering sedation did not hold Advanced Paediatric Life Support qualification.

$84.2-100 \%$ of the participating centres reported that oxygen saturations, respiration and heart rate were monitored routinely; BP was monitored by 7 (36.8\%), and ECG monitoring by 2 centres $(10.5 \%) .5(26.3 \%)$ centres reported at least one adverse cardiorespiratory event during sedation.

Conclusion We could not identify any centres that were able to implement the KPIs fully for routine scan sedations, raising questions about possible practical issues. This warrants further exploration into the practical experiences of different centres. We hope to initiate a discussion aiming to weigh the benefits and practical difficulties of the sedation guidelines.

\section{PARENT PRIORITIES AND PREFERENCES AT THE OUTPATIENT VISIT}

doi:10.1136/archdischild-2012-302724.1683

M Elbadry, AM Deasy, MB O’Neill. Mayo General Hospital, Castlebar, Ireland

Background and Aims The outpatient care model for children is well established. This study evaluated parent perceptions and understanding of this service in a District General Hospital.

Methods Parents attending a paediatric outpatient clinic were surveyed to discern their health priorities for their child, their understanding of the functioning of the outpatient clinic, the cost accrued by the visit and their views on alternate care delivering systems.

Results Two hundred and forty three surveys were completed by parents. Forty five (18.8\%) had children less than 1 year, 91 (38.1\%) were between 1 and 5 years, 50 (20.9) were aged 6 to 10 and the remainder were 11 or older. For $202(84.2 \%)$ it was a return visit. Their priorities were.

1. obtaining a diagnosis

2. achieving health gain for their child.

3. being reassured.

4. being seen by a consultant.

5. being treated with courtesy.

6. having tests performed.

Ninety three $(44.5 \%)$ were aware of how the clinic operated and $112(49.1 \%)$ wished to be seen by a consultant only. To attend the clinic $84(37.2 \%)$ took time off work, 50 (22.6\%) required child minding services, 44 (27\%) experienced excessive waiting and 198 (88\%) accrued parking costs. One hundred and forty three $(71.8 \%)$ are open to alternate care options other than the traditional outpatient visit with 141 (68.1\%) accepting specialist nurse assessment, $122(55.5 \%)$ postal assessment, and $56(25.2 \%)$ telephone assessment by a doctor.

Conclusion The model of outpatient care has changed little in the past decades. While parents understand the process there is active interest in pursuing more family friendly models.

\section{IMPACT OF TRANSITIONAL CARE SERVICE AND COMMUNITY CHILDREN'S NURSING (CCN) TEAM ON LONG STAY ADMISSIONS IN A DGH PAEDIATRIC UNIT}

doi:10.1136/archdischild-2012-302724.1684

N Corrigan, C Campbell. Paediatrics, Altnagelvin Area Hospital, Derry, UK

In the original audit (1998-2001) medical, nursing, social and resource issues contributing to long stay paediatric admissions (>100 days) were identified. 11 children were found with stays in excess of 100 days (4505 bed days) with an estimated cost of $£ 1.5$ million. It was also shown that, over time, social and resource factors became the predominant reasons preventing children's discharge, rather than medical or nursing issues.

As a result our Trust developed a services package aimed at facilitating early discharge and maintaining home placements for children with complex needs, including a Transitional Care Team, which provides care within the hospital based Transitional Care Unit and community settings. Additionally, there is a Community Paediatric Nursing Team who facilitate care packages, respite and competency based training for those involved in the children's care. Furthermore, there is a dedicated community paediatrician with expertise in palliative care.

We have repeated the audit 10 years later. Only 5 children stayed over 100 days resulting in 625 bed days (mean 125). This was an $86.1 \%$ reduction in bed days for patients staying greater than 100 days. Case note review suggests that in $80 \%(4 / 5)$ of these cases the primary reason for prolonged hospitalisation was the child's intensive medical and nursing needs. In addition the 4 children, for whom service involvement documentation was available, had active involvement from our new services.

We believe this audit confirms our impression that development of expert community based care has significantly contributed to shortening stays for our most complex and vulnerable children.

\section{MOOD DISORDERS IN POSTPARTUM PERIOD AT A RURAL TEACHING HOSPITAL IN WESTERN INDIA}

doi:10.1136/archdischild-2012-302724.1685

1,2SM Nimbalkar, 'AS Nimbalkar, ' $\mathrm{H}$ Patel, 'NS Chaudhary, ${ }^{1} \mathrm{KV}$ Gadhavi, ${ }^{2} \mathrm{JD}$ Ganjiwale, ${ }^{3} \mathrm{R}$ Vasa, 'SN Vani. 'Department of Pediatrics, Pramukhswami Medical College; ${ }^{2}$ Central Research Services, Charutar Arogya Mandal, Anand, India; ' 2 Department of Pediatrics, Mercy Hospital, Chicago, IL, USA

Background and Aims Post Partum Blues/Mood Disorders affects $50-80 \%$ of women in the first two weeks Post partum. Post partum depression affects $10 \%$ of women and post partum psychosis affects $1 / 1000$ women.

\section{Methods}

1. Determine ease and feasibility of EPDS in State of Gujarat, India.

2. Determine incidence of post partum mood disorders/blues in Anand district, Gujarat.

Women delivering beyond 30 weeks at Shri Krishna Hospital, Karamsad were asked to complete EPDS survey within a week of Delivery (after informed consent). The EPDS form was translated in Gujarati language. The study was conducted for one month. EPDS score of 10.5 or more was considered high risk.

Results The prevalence of post partum blues was $48.5 \%$. Factors associated with post partum blues were birth weight, difficulty in breastfeeding, mother's worries about the infant and whether pregnancy unwanted. $90 \%$ of the women with unwanted pregnancy had mood disorder. Addiction of husband and violence from husband were also associated to the mood disorder of the new mother. Infant death was not found to be associated with mood disorder in mothers as mothers with infants surviving as well were 
proportionately found to have mood disorder. Gender of child did not show any association with the post partum blues in the mother. Conclusion Post partum blues has a higher prevalence of $49 \%$ in our region. In India we need to study both the immediate post partum blues and post partum depression to understand their effects on child health.

\section{REVIEW OF CYCLICAL VOMITING SYNDROME IN A GENERAL PAEDIATRIC HOSPITAL OVER A 12 YEAR PERIOD}

doi:10.1136/archdischild-2012-302724.1686

K Odumusi, MJ Mahony, K Atif, B Jamal, C Obi, AM Murphy. Paediatrics, University Hospital Limerick, Limerick, Ireland

Background and Aims Cyclical vomiting syndrome (CVS) is a chronic disorder characterised by recurrent episodes of vomiting separated by symptom free periods. Aim is to review the epidemiology, history, investigation and treatment of children diagnosed with CVS in Mid Western Regional Hospital Limerick from January 2000 to December 2011.

Methods This is a retrospective study of the cases that met the criteria for the diagnosis of CVS. Cases were identified using the hospital in-patient enquiry scheme (HIPE) data. Each patient's case file was assessed for the review.

Results A total of 89 cases of recurrent vomiting were identified using the HIPE data. 10 cases of CVS were identified. Age of onset ranged from 5 to 13 years. $8(80 \%)$ of patients were female. There was an average of 18 months between the onset of symptoms and establishment of diagnosis. Average duration of vomiting episodes was 5 days and average frequency was 6 weekly. $1(10 \%)$ had a positive family history of CVS while $4(40 \%)$ had a family history of migraine. $3(30 \%)$ had associated migraine. $9(90 \%)$ of patients had abdominal $x$-ray and upper GI contrast study while $5(50 \%)$ had upper GI endoscopy and abdominal ultrasound scan. 3(30\%) had brain MRI and $1(10 \%)$ had laparoscopy and MRCP. $9(90 \%)$ of patients were treated with ondasetron, $8(80 \%)$ with proton pump inhibitors and 3(30\%) with cyclizine during episodes. 2(20\%) required psychiatric input.

Conclusions CVS is a disabling condition with female predominance. There is often a delay in diagnosis and large expenditure on investigations before diagnosis is made.

\section{STUDY OF CHILDREN OF BURN VICTIMS ADMITTED IN A BRAZILIAN TEACHING PUBLIC HOSPITAL}

doi:10.1136/archdischild-2012-302724.1687

'NV Moliterno, ' $F$ Moliterno, 'A Veiga, 'EO Veiga, ${ }^{2} S$ Maciel, ${ }^{2} \mathrm{MP}$ Branco, 'S Stumpf, 'SA Nogueira, 'CC Mochdece, 'AP Perie, ' $\mathrm{G}$ Benvenuti, ${ }^{3} \mathrm{DV}$ Rodrigues. 'Faculdade de Medicina de Petrópolis; ${ }^{2}$ Hospital Alcides Carneiro; ${ }^{3}$ Pediatria, Faculdade de Medicina de Petrópolis, Petrópolis, Brazil

Background and Aims The injuries are among the leading causes of morbidity and mortality of children and adolescents. As burns takes the second place in the world of accidents, it is important to be prevented. The aim of this study is describe data from patients hospitalized in a public pediatric unit with a diagnosis of burns in hospital admission.

Methods Cross sectional analysis of documentary records of patients admitted into the Unit of Pediatrics Teaching Hospital in the mountainous region of the State of Rio de Janeiro from May 2009 to May 2011.

Results A total of 29 patients, five (17.24\%) required intensive care. The mean age was 5.73 years and duration of hospitalization was 18.17 days. Predominated by males (65.51\%). The average age of the ICU was 4.6 years with a predominance of males $(60 \%)$ and length of hospital stay was 12.6 days. The heated liquid is the main causative agent, the mean body surface area affected was $42 \%$. Mechanical ventilation of $40 \%$ of patients and hemodynamic support with vasoactive $80 \%$, the mean sedation was 192 hours and the mean of beginning the diet was 43.2 hours, and is the most used jejunal $(60 \%)$. Three patients made use of hyperbaric therapy, with good resolution.

Conclusions The burns are an important public health problem, efforts are needed to reduce accidents and the large number of victims, because the main form of "treatment" for the burn is still prevention through the application of epidemiological principles awareness campaigns and legislative measures.

\section{HOSPITAL@HOME - AN INNOVATIVE COST EFFECTIVE APPROACH TO PAEDIATRIC CARE IN COMMUNITY}

doi:10.1136/archdischild-2012-302724.1688

'S Jyothi, ${ }^{2} \mathrm{~A}$ Vasudevan, ${ }^{3} \mathrm{M}$ Hubbard, ${ }^{4} \mathrm{C}$ Morris, ${ }^{5} \mathrm{~V}$ Yuvaraj. 'Birmingham Children's Hospital, Birmingham; ${ }^{2}$ Longton Hall Surgery; ${ }^{2}$ University Hospital of North Staffordshire; ${ }^{4}$ Staffordshire and Stoke on Trent Partnership Trust, Stoke on Trent; ${ }^{5}$ The John Kelso Practice, Leek, UK

Background A survey in 2009-10 in our region showed 60\% of the total 5500 admissions were discharged from paediatric admissions unit within 4 hours with no active clinical intervention. In early 2011 Local Health Economy(LHE)group consisting of GPs and Paediatricians devised an innovative approach for existing $\mathrm{H} @ \mathrm{H}$ team to manage children with acute illnesses at home and prevent hospital attendance.

Aims To prevent unnecessary hospital attendances and offer a safe cost-effective alternative to short stay admissions by providing clinical care for children at home.

Methods The new H@H service was promoted by GP practice visits and various educational events by the team before commencing in April 2011. Following assessment by GPs, children who needed observation for their acute illnesses and were appropriate to be managed at home were referred to H@H. The H@H team followed local guidelines for management of these children at home and any deterioration in the clinical condition prompted referral to the PAU. Results Until now H@H has been utilised by 90 of 100 GP practices in our region. 950 children were referred and managed by $\mathrm{H} @ \mathrm{H}$ with no adverse events till date. H@H has crossed the conservative cost effective target of reducing 4 PAU referrals each day with a projected saving of $£ 181,000$ /annum. The feedback has been positive from all service users.

Conclusions The two streams of $\mathrm{H} @ \mathrm{H}$

i. early discharge facility

ii. cost-effective admission avoidance facility have proved successful in our region and is currently being evaluated to be introduced by other regions.

\section{REDUCING REFERRALS TO SECONDARY CARE - AN INNOVATIVE APPROACH}

doi:10.1136/archdischild-2012-302724.1689

${ }^{1} \mathrm{~S}$ Jyothi, ${ }^{2} \mathrm{G}$ Julia, ${ }^{2 \mathrm{H}}$ Jenny, ${ }^{3} \mathrm{~A}$ Vasudevan, ${ }^{4} \mathrm{M}$ Hubbard, ${ }^{5} \mathrm{~V}$ Yuvaraj. ${ }^{1}$ Birmingham Childens Hospital, Birmingham; ${ }^{2}$ Partnership in Paediatrics; ${ }^{3}$ Longton Hall Surgery: ${ }^{4}$ University Hospital of North Staffordshire, Stoke on Trent; ${ }^{5}$ The John Kelso Practice, Leek, UK

Background A recent survey showed that in 2009/10 there were approximately 5,500 paediatric admissions in our region. $62 \%$ of these were children referred by GP and $70 \%$ were discharged within 4 hours without active clinical intervention. NHS Stoke-on-Trent, NHS North Staffordshire and Partners in Paediatrics (PiP) devised an innovative approach between primary and secondary care 